\title{
EBV-Positive Diffuse Large B-Cell Lymphoma, Not Otherwise Specified
}

National Cancer Institute

\section{Source}

National Cancer Institute. EBV-Positive Diffuse Large B-Cell Lymphoma, Not Otherwise Specified. NCI Thesaurus. Code C80281.

A diffuse large B-cell lymphoma originally described in patients older than 50 years but it has been increasingly recognized in young er patients. Epstein-Barr virus is present in all cases. There is no known history of immunodeficiency or prior lymphoma. 